\title{
APLIKASI AKAIKE INFORMATION CRITERION (AIC) PADA PERHITUNGAN EFISIENSI TEKNIS PERIKANAN PUKAT CINCIN DI TUBAN, JAWA TIMUR
}

\author{
Akaike Information Criterion (AIC) in Measurement of Technical Efficiency of Purse \\ Seine Fishery in Tuban, East Java
}

Oleh:

\author{
Ledhyane Ika Harlyan ${ }^{*}$, Eko Sulkhani Yulianto², Yulis Fitriani ${ }^{3}$, Sunardi ${ }^{4}$ \\ ${ }^{1}$ Fakultas Perikanan dan Ilmu Kelautan, Universitas Brawijaya, ledhyane@ub.ac.id \\ 2 Fakultas Perikanan dan Ilmu Kelautan, Universitas Brawijaya, ekosulkhaniy@ub.ac.id \\ ${ }^{3}$ Fakultas Perikanan dan Ilmu Kelautan, Universitas Brawijaya, yulis.fitriani96@gmail.com \\ ${ }^{4}$ Fakultas Perikanan dan Ilmu Kelautan, Universitas Brawijaya, sunardi@ub.ac.id \\ *Korespondensi: ledhyane@ub.ac.id
}

Diterima: 18 September 2020; Disetujui: 30 November 2020

\begin{abstract}
Purse seine fishery in Tuban has contributed to generating high catch variation by applying various fishing operations which are reflected in four production factors, such as boat size, fishing ground, number of trips, and crews. The data was collected through fishery surveys and interviews with 60 fishers. Akaike Information Criterion (AIC) was applied to obtain the best production model over various regression models by comparing the maximum likelihood. This study was aimed to attain the best model which can produce an optimum catch. Over all production factors, the number of trips was the prominent variable determining catch. Synchronization between the information of an optimum trip and the allowable biological effort might be applied for purse seine fishery management in Tuban.
\end{abstract}

Keywords: boat size, fishing ground, number of trips, number of crews, production factors.

\begin{abstract}
ABSTRAK
Perikanan pukat cincin di Tuban memiliki kontribusi yang tinggi dalam menciptakan variasi hasil tangkapan. Hal ini disebabkan oleh beragamnya metode pengoperasian yang digunakan dan tergambar pada empat faktor produksi yaitu ukuran kapal, jarak daerah penangkapan ikan, jumlah trip dan jumlah anak buah kapal (ABK) yang diambil dengan metode wawancara kepada 60 responden. Metode Akaike Information Criterion (AIC) merupakan metode analisis yang digunakan untuk memperoleh model faktor produksi yang terbaik dengan menggunakan estimasi maximum likelihood sebagai perhitungan yang sesuai. Penelitian ini bertujuan untuk mengetahui model produksi terbaik dengan menggunakan AIC sehingga diperoleh hasil tangkapan yang optimal. Hasil penelitian menunjukkan bahwa jumlah trip merupakan variabel penentu kuantitas hasil tangkapan. Sinkronisasi informasi jumlah trip optimal dan ketentuan upaya penangkapan yang diperbolehkan dapat dijadikan dasar pengelolaan perikanan perikanan pukat cincin di Tuban.
\end{abstract}

Kata kunci: faktor produksi, ukuran kapal, jarak DPI, jumlah trip, jumlah ABK. 


\section{PENDAHULUAN}

Eksploitasi sumber daya perikanan yang berlebihan dapat terjadi pada kondisi open access yang memungkinkan tidak adanya regulasi terkait aktivitas penangkapan. Pada kondisi ini, jumlah kapasitas penangkapan relatif lebih besar dibandingkan tingkat optimal yang mengarah pada terjadinya disipasi keuntungan ekonomi dan punahnya stok ikan (Kroetz et al. 2013). Pada sektor industri, termasuk di dalamnya industri perikanan tangkap, secara teknis telah dilakukan pengembangan produksi dan analisis efisiensi (Van Nguyen et al. 2021). Nelayan cenderung mengubah strategi penangkapan dengan intensifikasi input kegiatan penangkapan untuk meningkatkan produktivitas dan efisiensi mereka. Pada beberapa kasus, inefisiensi dalam kegiatan penangkapan dapat terjadi karena ketidakseimbangan jumlah input yang dikeluarkan dan output yang dihasilkan. Dalam hal ini adalah tingginya upaya penangkapan tidak mampu menghasilkan produksi dan nilai produksi yang seimbang (Wiyono dan Hufiadi 2014).

Perikanan pukat cincin merupakan perikanan yang memberikan proporsi besar pada produksi perikanan pelagis dan memegang peranan penting dalam perikanan Indonesia. Pukat cincin juga merupakan alat tangkap yang mendominasi sebesar $40 \%$ dari total alat tangkap berlisensi di Indonesia. Sementara hasil produksi pukat cincin adalah sebesar $30 \%$ dari total produksi perikanan Indonesia (Kementerian Kelautan dan Perikanan 2018).

Secara umum, operasi penangkapan pukat cincin memiliki beberapa faktor produksi yang dapat dimodifikasi besaran inputnya untuk memastikan besaran output produktivitas yang dihasilkan, seperti misalnya dimensi alat tangkap, tonase kapal, jumlah anak buah kapal (ABK), jumlah trip, jumlah hari melaut dan kebutuhan bahan bakar (Johannes et al. 2015; Pratama et al. 2016). Oleh karena itu, penilaian jenis faktor produksi dan besarannya dalam operasi penangkapan pukat cincin sangat penting untuk digunakan sebagai referensi dalam pengaturan kapasitas penangkapan sehingga menghasilkan keuntungan yang optimal.

Beberapa studi mendokumentasikan evaluasi teknis jenis dan besaran faktor produksi pada perikanan pukat cincin di Indonesia dengan menerapkan model produksi tertentu (Wiyono dan Hufiadi 2014; Johannes et al. 2015). Namun komparasi beberapa model untuk menentukan model yang paling tepat untuk data faktor produksi yang tersedia belum banyak dilakukan, terutama untuk penilaian faktor produksi perikanan pukat cincin.

Akaike information criterion (AIC) merupakan penilaian yang diaplikasikan untuk menentukan model terbaik di antara beberapa model produksi. AIC dapat diaplikasikan sebagai model selektor yang mampu mengasesi kualitas tiap model secara relatif dengan menggunakan estimasi maximum likelihood sebagai pehitungan yang sesuai (Anderson et al. 1998). Kajian ini bertujuan untuk mengetahui model produksi terbaik dengan menggunakan aplikasi AIC untuk memperoleh hasil tangkapan yang optimal. Beberapa faktor produksi ditempatkan sebagai variabel pada beberapa model produksi dan untuk selanjutnya dilakukan pengujian dan komparasi untuk mendapatkan model yang paling sesuai dari keseluruhan model produksi.

\section{METODE}

Penelitian dilakukan di Pelabuhan Perikanan Pantai (PPP) Bulu, Tuban (Gambar 1) dengan periode pengambilan data adalah Oktober - November 2019.

Pengambilan data dilakukan dengan menggunakan satu set kuesioner dengan menggunakan metode purposive sampling yakni dilakukan pemilihan responden nelayan pukat cincin yang baru mendaratkan hasil tangkapan. Sebanyak 60 orang responden nelayan yang dipilih merupakan nakhoda atau pemilik kapal pukat cincin, yang beroperasi di Perairan Tuban dan mendaratkan hasil tangkapannya di Pelabuhan Perikanan Pantai (PPP) Bulu, Tuban.

Kuesioner digunakan untuk menggali data dan informasi yang berkaitan dengan operasi penangkapan dengan menggunakan armada pukat cincin yang beroperasi di perairan sekitar pantai utara dan mendaratkan hasil tangkapannya di PPP Bulu. Variabel data yang dikumpulkan untuk tiap responden adalah data hasil tangkapan, daerah penangkapan ikan (DPI), ukuran kapal dan jumlah anak buah kapal (ABK).

Analisis data yang digunakan dalam kajian ini adalah analisis faktor produksi. Hubungan teknis antara variabel faktor produksi akan dianalisis untuk menghasilkan produktivitas paling tinggi dengan menggunakan fungsi produksi regresi linier. Dalam hal ini, beberapa informasi penting pada operasi penangkapan dengan armada pukat cincin yaitu DPI, daya mesin, ukuran kapal 
dan panjang jaring diasumsikan sebagai variabel regresi. Faktor-faktor tersebut dianggap menjadi variabel penentu produksi perikanan pukat cincin.

\section{Penentuan model faktor produksi}

Pada perhitungan faktor produksi, beberapa model regresi linier dianalisis. Akaike information criterion (AIC) digunakan untuk memperoleh model yang paling sesuai dengan variabel data yang diperoleh. AIC dapat dihitung dengan menggunakan persamaan:

$A I C=2 K-2 \ln (L)$

dengan $\mathrm{K}$ merupakan jumlah variabel independen yang digunakan dan $L$ merupakan Log-likelihood estimator yang mampu memproduksi variabel y yang diobservasi. Komparasi menggunakan AIC dilakukan dengan melakukan perhitungan simultan skor AIC dan L. Pada kajian ini, perhitungan AIC, LL dan beberapa parameter dilakukan dengan menggunakan software R packages AlCcmodavg.

Berikut ini adalah 15 model regresi linier yang dianalisis dan untuk selanjutnya dikomparasi.

Model Tunggal:

$Y=b_{0}+b_{1} \cdot x_{1}$
$Y=b_{0}+b_{2} \cdot X_{2}$
$Y=b_{0}+b_{3} \cdot X_{3}$
$Y=b_{0}+b_{4} \cdot X_{4}$

Model kombinasi :

$Y=b_{0}+b_{1} \cdot x_{1}+b_{2} \cdot x_{2}$

$Y=b_{0}+b_{1} \cdot x_{1}+b_{3} \cdot x_{3}$

$Y=b_{0}+b_{1} \cdot x_{1}+b_{4} \cdot x_{4}$

$Y=b_{0}+b_{2} \cdot x_{2}+b_{3} \cdot x_{3}$

$Y=b_{0}+b_{2} \cdot x_{2}+b_{4} \cdot x_{4}$

$Y=b_{0}+b_{1} \cdot x_{1}+b_{2} \cdot x_{2}+b_{3} \cdot x_{3}$

$Y=b_{0}+b_{1} \cdot x_{1}+b_{2} \cdot x_{2}+b_{4} \cdot x_{4}$

$Y=b_{0}+b_{2} \cdot x_{2}+b_{3} \cdot x_{3}+b_{4} \cdot x_{4}$

$Y=b_{0}+b_{1} \cdot x_{1}+b_{3} \cdot x_{3}+b_{4} \cdot x_{4}$

$Y=b_{0}+b_{1} \cdot x_{1}+b_{2} \cdot x_{2}+b_{3} \cdot x_{3}+b_{4} \cdot x_{4}$

Model interaksi :

$\mathrm{Y}=\mathrm{b}_{0} \times \mathrm{b}_{1} \cdot \mathrm{x}_{1} \times \mathrm{b}_{2} \cdot \mathrm{x}_{2} \times \mathrm{b}_{3} \cdot \mathrm{x}_{3} \times \mathrm{b}_{4} \cdot \mathrm{x}_{4}$ dengan:

$$
\begin{aligned}
& \mathrm{b}_{0}=\text { intercept } \\
& \mathrm{b}_{1}=\text { koefisien regresi ukuran kapal } \\
& \mathrm{X}_{1}=\text { ukuran kapal }(\mathrm{GT}) \\
& \mathrm{b}_{2}=\text { koefisien regresi jarak DPI } \\
& \mathrm{X}_{2}=\text { jarak DPI (mil) } \\
& \mathrm{b}_{3}=\text { koefisien regresi jumlah trip } \\
& \mathrm{X}_{3}=\text { jumlah trip } \\
& \mathrm{b}_{4}=\text { koefisien regresi jumlah ABK } \\
& \mathrm{X}_{4}=\text { jumlah ABK (orang) } \\
& \mathrm{Y}=\text { Hasil tangkapan }(\mathrm{kg})
\end{aligned}
$$

Sebanyak 15 model yang akan diujikan dan dikomparasi untuk menentukan model terbaik yang memiliki prediksi galat terkecil dengan menggunakan jumlah parameter and prediksi maximum likelihood. Terdapat empat model, merupakan model tunggal dengan satu variabel regresi, masing-masing untuk variabel ukuran kapal, jarak DPI, jumlah trip dan jumlah ABK. Lima model disusun dari dua variabel regresi, empat model disusun dari tiga variabel regresi, dan dua model disusun dari empat variabel regresi.

\section{Penentuan model faktor produksi terbaik}

Penentuan faktor produksi yang paling sesuai dilakukan dengan memperhatikan hasil perhitungan software $\mathrm{R}$ :

- Model yang paling sesuai akan muncul paling awal.

- Nilai AICc merupakan informasi skor yang telah terkoreksi untuk tiap model. Model yang memiliki nilai AIC paling kecil merupakan model terbaik.

- Nilai Delta AIC merupakan nilai yang menunjukkan perbedaan skor AIC model terbaik dan model lain yang dikomparasi.

- Nilai AIC weight merupakan proporsi jumlah total prediksi yang disediakan oleh data set yang muncul pada model.

- Nilai Cum.Wt merupakan jumlah bobot $\mathrm{AICc}$

- Nilai LL merupakan log likelihood yang menggambarkan kemungkinan model tersebut dapat diaplikasikan. 


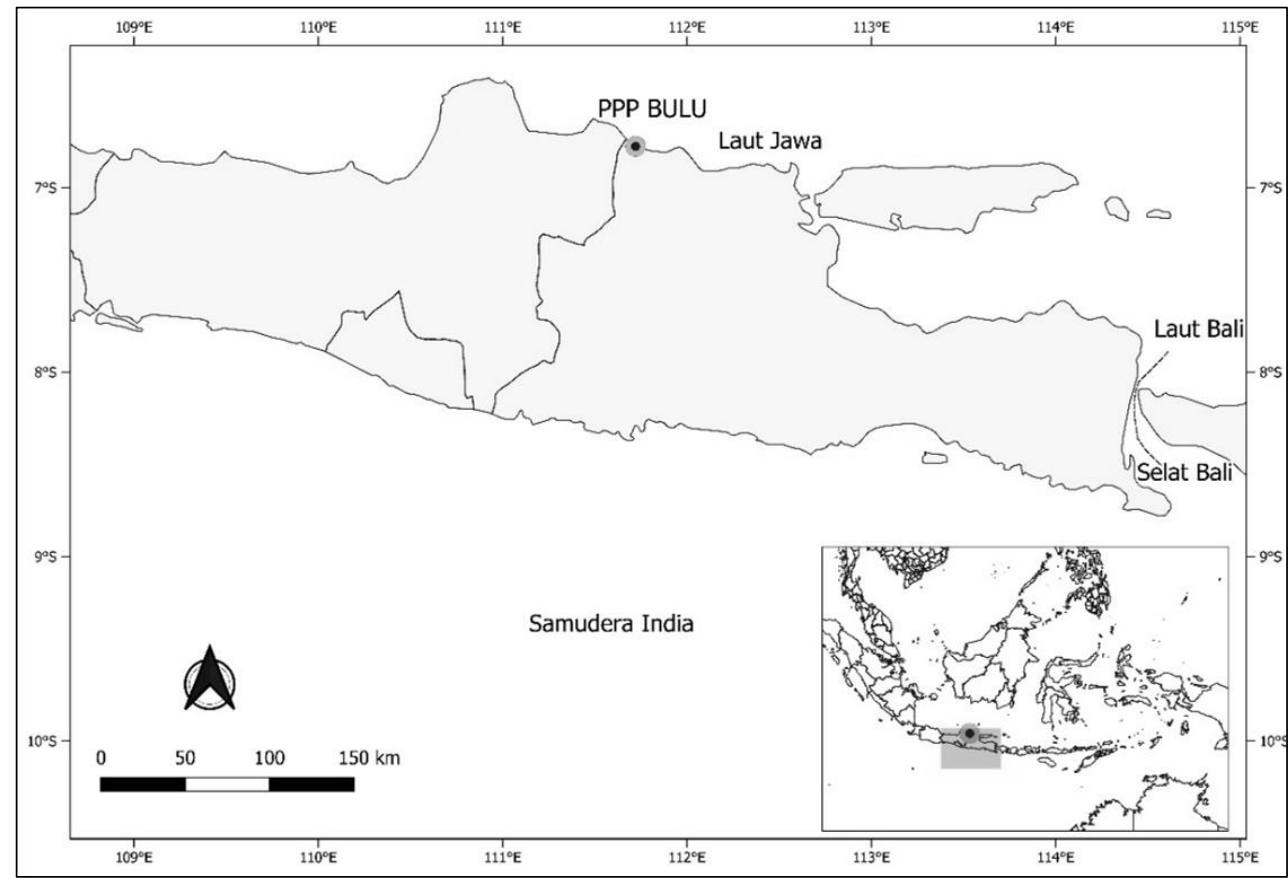

Gambar 1 Peta Lokasi Penelitian

HASIL

Pukat cincin merupakan alat tangkap dominan keempat yang dioperasikan di Perairan Tuban (Gambar 2), setelah alat tangkap dogol, bubu dan gillnet. Meski demikian, menurut nelayan setempat, jumlah nelayan yang mengoperasikan alat tangkap ini mengalami peningkatan dari tahun ke tahun. Dalam satu armada, jumlah $A B K$ yang digunakan berkisar antara 8 - 10 orang dengan jumlah trip 180 $260 \mathrm{trip} / \mathrm{kapal} /$ tahun.

Keberhasilan pengoperasian pukat cincin juga tidak lepas dari jarak DPI yang ditempuh. Penentuan DPI pada perikanan pukat cincin Bulu terletak pada kisaran 11 - 35 mil dari garis pantai. Pada musim tangkapan tinggi, DPI berada pada pada kisaran 13 mil, namun pada musim tangkapan rendah, maka nelayan Bulu harus menangkap ikan makin jauh hingga di luar perairan Tuban.

Demikian halnya dengan ukuran kapal yang diasumsikan akan mampu mempengaruhi kuantitas hasil tangkapan. Semakin besar ukuran kapal, maka semakin mampu menampung jumlah ikan hasil tangkapan. Ukuran kapal pukat cincin yang dioperasikan di perairan Bulu adalah 13 - 33 GT dengan daya mesin 120 PS. Kapal-kapal tersebut melakukan kegiatan penangkapan satu hari trip bergantung pada cuaca setempat. Pukat cincin yang dioperasikan memiliki kedalaman jaring kurang lebih $100 \mathrm{~m}$ dengan ukuran mata jaring sebesar 1 inch.
Variasi metode pengoperasian menyebabkan tingginya variasi hasil tangkapan armada pukat cincin yang dioperasikan di perairan tersebut. Berdasarkan set data dari beberapa variabel faktor produksi dihasilkan beberapa variasi model yang memiliki probabilitas terbaik dalam menghasilkan hasil tangkapan pukat cincin yang tinggi.

Pemilihan model AIC digunakan untuk membedakan antara beberapa set model yang memiliki probabilitas mampu menggambarkan hubungan antara ukuran kapal, jarak DPI, jumlah trip dan jumlah ABK. Berdasarkan hasil perhitungan AIC (Tabel 1), diperoleh bahwa model tunggal yang menggunakan variabel trip merupakan model terbaik dengan skor AICc terkecil. Begitu pula dengan skor AICcWt yang paling besar menunjukkan bahwa model ini model paling sesuai yang memiliki bobot kumulatif yang menyertakan setiap variabel tanpa efek interaksi.

Model regresi linier sederhana antara jumlah trip dan hasil tangkapan (Gambar 3) menunjukkan korelasi positif yang mengindikasikan adanya setiap peningkatan satu trip penangkapan akan mengakibatkan adanya peningkatan jumlah hasil tangkapan sebesar 107,63 ton. Model regresi ini mampu memperlihatkan bahwa variabel bebas jumlah trip secara tunggal mampu menjelaskan variabel tak bebas hasil tangkapan sebesar $56 \%$. 


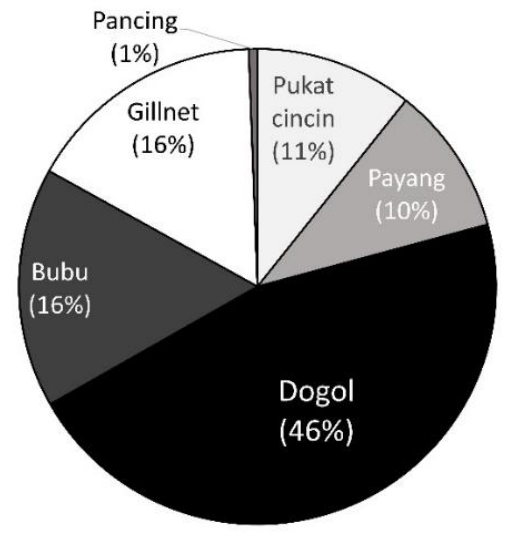

Gambar 2 Proporsi alat tangkap yang dioperasikan di Perairan Tuban

Tabel 1 Hasil komparasi AIC

\begin{tabular}{|c|c|c|c|c|c|c|}
\hline Model & $\mathrm{K}$ & AICc & $\begin{array}{l}\text { Delta } \\
\text { AlCc }\end{array}$ & AICcWt & $\begin{array}{c}\text { Cum. } \\
\text { Wt }\end{array}$ & $\overline{L L}$ \\
\hline$Y=b_{0}+b_{3} \cdot x_{3}$ & 3 & 1222,70 & 0,00 & 0,46 & 0,46 & $-608,13$ \\
\hline$Y=b_{0}+b_{2} \cdot x_{2}+b_{3} \cdot x_{3}$ & 4 & 1224,74 & 2,05 & 0,16 & 0,62 & $-608,01$ \\
\hline$Y=b_{0}+b_{1} \cdot x_{1}+b_{3} \cdot x_{3}$ & 4 & 1224,98 & 2,28 & 0,15 & 0,76 & $-608,13$ \\
\hline$Y=b_{0}+b_{2} \cdot x_{2}+b_{3} \cdot x_{3}+b_{4} \cdot x_{4}$ & 5 & 1226,07 & 3,37 & 0,08 & 0,85 & $-607,48$ \\
\hline$Y=b_{0}+b_{1} \cdot x_{1}+b_{3} \cdot x_{3}+b_{4} \cdot x_{4}$ & 5 & 1226,33 & 3,63 & 0,07 & 0,92 & $-607,61$ \\
\hline$Y=b_{0}+b_{1} \cdot x_{1}+b_{2} \cdot x_{2}+b_{3} \cdot x_{3}$ & 5 & 1227,09 & 4,40 & 0,05 & 0,97 & $-607,99$ \\
\hline $\begin{array}{c}Y=b_{0}+b_{1} \cdot x_{1}+b_{2} \cdot x_{2}+b_{3} \cdot x_{3} \\
+b_{4} \cdot x_{4}\end{array}$ & 6 & 1228,49 & 5,79 & 0,03 & 1,00 & $-607,45$ \\
\hline $\begin{array}{r}Y=b_{0} \times b_{1} \cdot x_{1} \times b_{2} \cdot x_{2} \times b_{3} \cdot x_{3} \\
\times b_{4} \cdot x_{4}\end{array}$ & 17 & 1234,37 & 11,67 & 0,00 & 1,00 & $-592,90$ \\
\hline$Y=b_{0}+b_{4} \cdot x_{4}$ & 3 & 1242,92 & 20,22 & 0,00 & 1,00 & $-618,24$ \\
\hline$Y=b_{0}+b_{1} \cdot x_{1}$ & 3 & 1244,08 & 21,39 & 0,00 & 1,00 & $-618,83$ \\
\hline$Y=b_{0}+b_{2} \cdot x_{2}$ & 3 & 1244,51 & 21,82 & 0,00 & 1,00 & $-619,04$ \\
\hline$Y=b_{0}+b_{1} \cdot x_{1}+b_{4} \cdot x_{4}$ & 4 & 1244,73 & 22,03 & 0,00 & 1,00 & $-618,00$ \\
\hline$Y=b_{0}+b_{2} \cdot x_{2}+b_{4} \cdot x_{4}$ & 4 & 1245,21 & 22,52 & 0,00 & 1,00 & $-618,24$ \\
\hline$Y=b_{0}+b_{1} \cdot x_{1}+b_{2} \cdot x_{2}$ & 4 & 1246,37 & 23,68 & 0,00 & 1,00 & $-618,82$ \\
\hline$Y=b_{0}+b_{1} \cdot x_{1}+b_{2} \cdot x_{2}+b_{4} \cdot x_{4}$ & 5 & 1247,09 & 24,39 & 0,00 & 1,00 & $-617,99$ \\
\hline
\end{tabular}

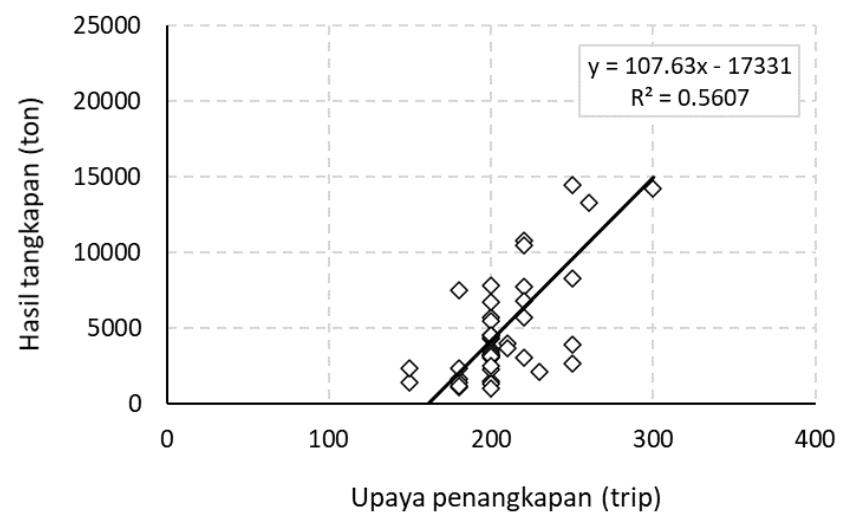

Gambar 3 Model regresi antara jumlah trip dan hasil tangkapan 


\section{PEMBAHASAN}

Pada beberapa referensi, terdapat faktor produksi lain yang juga mempengaruhi kuantitas hasil tangkapan, misalnya adalah luas jaring (Picaulima 2012), lama trip, perbekalan (Wiyono dan Hufiadi 2014; Imanda et al. 2016), lebar dan kedalaman jaring, serta kekuatan mesin (Pratama et al. 2016). Pada kajian ini, ditemukan bahwa keberadaan faktor-faktor tersebut tidak memiliki variasi nilai yang mampu dibandingkan. Di lain sisi, faktor-faktor produksi pada penelitian ini merupakan faktor produksi yang memiliki keberagaman nilai untuk dapat dijadikan variabel pada beberapa model yang selanjutnya dibandingkan.

Pemilihan metode AIC pada pengolahan data analisis faktor produksi perikanan pukat cincin di Tuban, karena metode ini mampu mengkomparasi beberapa model. Beberapa model yang dikomparasi merupakan regresi linier sederhana yang terdiri dari satu faktor produksi dan model regresi berganda yang merupakan hasil kombinasi maupun interaksi antar faktor (Mcowen et al. 2015; Scarcella et al. 2015). Sementara pada metode lain, perhitungan analisis produksi dilakukan dengan menggunakan analisis Cobb-Douglas (Johannes et al. 2015; Pratama et al. 2016; Polhaipessy et al. 2020) yang menggunakan hanya satu model kombinasi yang melibatkan seluruh variabel faktor produksi yang dilibatkan tanpa menyertakan kemungkinan adanya variabelvariabel memiliki pengaruh simultan dengan model yang lain.

Berdasarkan hasil komparasi beberapa model regresi, baik linier sederhana maupun berganda dengan menggunakan lebih dari satu variabel, model regresi tunggal dengan menggunakan variabel trip merupakan model terbaik yang mampu menjelaskan fungsi produksi perikanan pukat cincin. Variabel trip merupakan variabel yang mampu secara signifikan menjadi pengendali atas hasil tangkapan dengan korelasi positif. Peningkatan jumlah trip akan meningkatkan hasil tangkapan, demikian pula sebaliknya.

Dalam kurun waktu satu dekade, berdasarkan produktivitas, perikanan pukat cincin mengalami penurunan dengan meningkatnya kapasitas penangkapan yang ditandai dengan bertambahnya jumlah armada, perluasan DPI dan jumlah trip yang dioperasikan (Wiyono dan Hufiadi 2014; Purwanto dan Nugroho 2016). Namun mengingat produktivitas perikanan akan mengalami perubahan secara berkala sesuai dengan musim penangkapan maka alokasi jumlah trip yang boleh dioperasikan merupakan hal yang perlu dipertimbangkan demi keberlangsungan perikanan pukat cincin (Wiyono dan Hufiadi 2014).

Peningkatan jumlah trip yang didokumentasikan pada kajian ini membuktikan bahwa jumlah trip memberikan peningkatan hasil tangkapan lebih baik dibandingkan variabel produksi yang lain. Meski demikian usaha peningkatan kapasitas penangkapan perlu bersinergi dengan nilai upaya penangkapan yang diperbolehkan secara biologi yang didasarkan dari kemampuan sumber daya ikan untuk pulih akibat tekanan penangkapan (Harlyan et al. 2019; Harlyan et al. 2021). Pendugaan status stok sumber daya ikan pada perikanan pukat cincin di Tuban diperlukan sebagai dasar penentuan kebijakan alokasi upaya penangkapan termasuk diantaranya adalah penetapan jumlah trip/tahun yang boleh dilakukan.

\section{KESIMPULAN}

Hasil komparasi AIC terhadap beberapa model produksi menunjukkan bahwa variabel trip merupakan variabel pengendali hasil tangkapan dengan korelasi positif, dimana peningkatan jumlah trip akan meningkatkan hasil tangkapan. Meski demikian, demi perikanan yang berkelanjutan, perlu dipertimbangkan sinkronisasi hasil kajian ini dengan jumlah upaya penangkapan yang diperbolehkan yang merujuk pada potensi dan status sumber daya perikanan pukat cincin di Tuban.

\section{SARAN}

Diperlukan observasi dan analisis faktor produksi yang melibatkan faktor produksi lainnya yang dilakukan secara berkala untuk memperoleh dinamika perubahan faktor produksi pada perikanan pukat cincin di Tuban.

\section{UCAPAN TERIMA KASIH}

Peneliti mengucapkan terimakasih kepada Universitas Brawijaya atas pemberian Dana Program Penelitian Dosen Fakultas Perikanan dan IImu Kelautan Universitas Brawijaya. 


\section{DAFTAR PUSTAKA}

Anderson DR, Burnham KP, White GC. 1998. Comparison of Akaike Information Criterion and Consistent Akaike Information Criterion for Model Selection and Statistical Inference from Capture-Recapture Studies. Journal of Applied Statistics. 25(2): 263-282. DOI:10.1080/02664769823250.

Harlyan LI, Almawadah YA, Lelono TD. 2021. The Biological Aspects of Dominant Sharks and Rays Landed in Brondong Fishing Port, Lamongan, East Java. Journal of Environmental Engineering and Sustainable Technology. 8(1): 1016.

https://jeest.ub.ac.id/index.php/jeest/art icle/view/171.

Harlyan LI, Wu D, Kinashi R, Kaewnern M, Matsuishi T. 2019. Validation of A Feedback Harvest Control Rule in Datalimited Conditions for Managing Multispecies Fisheries. Canadian Journal Fisheries and Aquatic Science. 76(10): 1885-1893. DOI:10.1139/cjfas2018-0318.

Imanda SN, Setiyanto I, Hapsari TD. 2016. Analisis Faktor-Faktor yang Mempengaruhi Hasil Tangkapan Kapal Mini Purse Seine di Pelabuhan Perikanan Nusantara Pekalongan. Journal of Fisheries Resources Utilization Management and Technology. 5(1): 145-153.

https://ejournal3.undip.ac.id/index.php/jfrumt/ article/view/10747

Johannes S, Wisudo SH, Nurani TW. 2015. Analisis Faktor Produksi dan Kelayakan Usaha Perikanan Purse Seine di Kecamatan Salahutu Kabupaten Maluku Tengah. Jurnal Aplikasi Manajemen. 13(2): 335-343. https://jurnaliam.ub.ac.id/index.php/jam /article/view/774

Kementerian Kelautan dan Perikanan. 2018. Buku Pintar Kementerian Kelautan dan Perikanan 2018. Jakarta: Pusat Data, Statistik dan Informasi Kementerian Kelautan dan Perikanan.

http://sidatik.kkp.go.id/files/src/023dfaa95782 9d846cfb59164b6c5774.pdf.

Kroetz K, Sanchirico J, Fuller K, Kling D, Ross
N. 2013. Economics and Ecology of Open-Access Fisheries. In: Encyclopedia of Energy, Natural Resource, and Environmental Economics. p. 39-49. DOI: 10.1016/B978-0-12-375067-9.00114-5

Mcowen CJ, Cheung WWL, Rykaczewski RR, Watson RA, Wood LJ. 2015. Is Fisheries Production within Large Marine Ecosystems Determined by Bottom-up or Top-down Forcing? Fish and Fisheries. 16(4): 623-632. DOI: 10.1111/faf.12082.

Van Nguyen Q, Pascoe S, Coglan L, Nghiem S. 2021. The sensitivity of Efficiency Scores to Input and Other Choices in Stochastic Frontier Analysis: An Empirical Investigation. Journal of Productivity Analysis. 55(1): 31-40. DOI:10.1007/s11123-020-00592-8.

Picaulima S. 2012. Analisis Pengaruh Faktor Produksi Terhadap Produktivitas Perikanan Pukat Cincin di Kabupaten Maluku Tenggara. Journal of Tropical Fisheries. $\quad 7(1)$ : 611-616. https://ojs3.unpatti.ac.id/index.php/sem naskpfpik/article/download/2034/1681/

Polhaipessy R, Waileruny W, Matrutty D, Souisa F, Kemhay D. 2020. Analisis Faktor Produksi Usaha Perikanan Purse Seine di Pulau Ambon. Prosiding Seminar Nasional Kelautan dan Perikanan UNPATTI. DOI:10.30598/semnaskp-15.

Pratama MAD, Hapsari TD, Triarso I. 2016. Faktor-Faktor yang Mempengaruhi Hasil Produksi Unit Penangkapan Purse Seine (Gardan) di Fishing Base PPP Muncar, Banyuwangi, Jawa Timur. Saintek Perikanan: Indonesian Journal of Fisheries Science and Technology.11(2): 120-128. DOI: 10.14710/jifst.11.2.120-128.

Purwanto P, Nugroho D. 2016. Daya Tangkap Kapal Pukat Cincin dan Upaya Penangkapan pada Perikanan Pelagis Kecil di Laut Jawa. Jurnal Penelitian Perikanan Indonesia. 17(1):23-30. DOI: 10.15578/jppi.17.1.2011.23-30.

Scarcella G, Grati F, Bolognini L, Domenichetti $F$, Malaspina S, Manoukian S, Polidori P, Spagnolo A, Fabi G. 2015. Timeseries Analyses of Fish Abundance from An Artificial Reef and A Reference Area 
in the Central-Adriatic Sea. Journal of Applied Ichthyology. 31(S3): 74-85. DOI:10.1111/jai.12952.

Wiyono ES, Hufiadi H. 2014. Measuring the Technical Efficiency of Purse Seine in
Tropical Small-scale Fisheries in Indonesia. Asian Fisheries Science. 27(4):

297-308. 